\title{
EFECTO DEL ENVEJECIMIENTO ARTIFICIAL DE SEMILLAS DE MAÍCES CRIOLLOS AZULES EN SU GERMINACIÓN Y HUELLA GENÓMICA
}

\author{
EFFECT OF ARTIFICIAL SEED AGING ON BLUE MAIZE LANDRACES GERMINATION AND \\ GENOMIC FINGERPRINT
}

\author{
Germán F. Gutiérrez-Hernández ${ }^{*}$, Jorge M. Vázquez-Ramos ${ }^{2}$, Elpidio García-Ramírez ${ }^{2}$, Marina O. Franco- \\ Hernández ${ }^{3}$, José L. Arellano-Vázquez ${ }^{4}$ y Dagoberto Durán-Hernández ${ }^{1}$
}

Departamentos de ${ }^{1}$ Bioprocesos y ${ }^{3}$ Ciencias Básicas, Unidad Profesional Interdisciplinaria de Biotecnología, Instituto Politécnico Nacional. Av. Acueducto s/n. 07340, La Laguna Ticomán. México, D. F. ${ }^{2}$ Facultad de Química, Universidad Nacional Autónoma de México. Av. Universidad y Copilco, Ciudad Universitaria.

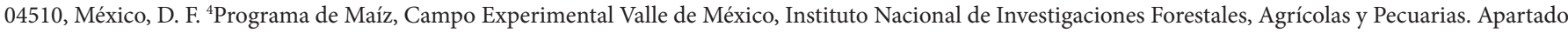
Postal 10. 56230, Chapingo, Edo. de México.

*Autor para correspondencia (enredipn@yahoo.com.mx).

\section{RESUMEN}

Para establecer su huella genómica y estimar su grado de tolerancia al envejecimiento, semillas de cuatro variedades criollas de maíz azul (Zea mays L.), 'Cuijingo', 'Cocotitlán', 'Puebla' y 'Oaxaca', se sometieron a dos tipos de envejecimiento artificial: calor húmedo $\left(\mathrm{CH}, 41{ }^{\circ} \mathrm{C}, 100\right.$ $\% \mathrm{HR}, 72 \mathrm{~h}$ ) y calor seco $\left(\mathrm{CS}, 60^{\circ} \mathrm{C}, 0 \% \mathrm{HR}, 48 \mathrm{~h}\right)$, con sus respectivos testigos no envejecidos. Las variables de respuesta fueron: protrusión radicular entre 0 y $72 \mathrm{~h}$ de imbibición y a $7 \mathrm{~d}$ de incubación a $25{ }^{\circ} \mathrm{C}$, número de plántulas normales, anormales y semillas muertas, así como peso seco de plúmula, radícula y total. Se hizo la caracterización molecular de los tratamientos mediante marcadores RAPDs y se construyeron dendrogramas. La protrusión radicular fue significativamente susceptible al $\mathrm{CH}$, mientras que el efecto del CS se expresó en reducción de plántulas normales y acumulación de materia seca, así como en mayor proporción de semillas muertas. Las semillas de la variedad 'Oaxaca' se distinguieron por su aptitud para la brotación radicular y por generar plántulas normales con alta capacidad para acumular biomasa, tanto en los testigos como en condiciones de calor húmedo. La huella genómica resultó específica para cada variedad, y en los dendrogramas las semillas se ramificaron con un coeficiente de similitud único para cada variedad: 'Oaxaca' (31.6 \%), 'Cocotitlán' (25.8 \%), 'Puebla' (19.6 $\%$ y 'Cuijingo' ( $18.6 \%$ ), valores que podrían estar relacionados con la capacidad genética para amortiguar, tolerar o restaurar los daños causados por el envejecimiento artificial sobre el ADN, la cual se manifestó directamente en un mejor desempeño fisiológico de las semillas de la variedad 'Oaxaca'.

Palabras clave: Zea mays, germinación, huella genómica, longevidad de semillas, RAPDs.

\section{SUMMARY}

In order to establish the genomic fingerprint and to estimate the degree of tolerance to aging, seeds from four blue maize landraces (Zea mays L.), 'Cuijingo', 'Cocotitlán', 'Puebla' and 'Oaxaca', were subjected to two types of artificial aging: humid heat $\left(\mathrm{HH}, 41{ }^{\circ} \mathrm{C}, 100 \% \mathrm{RH}, 72 \mathrm{~h}\right)$ and dry heat $\left(\mathrm{DH}, 60^{\circ} \mathrm{C}, 0 \% \mathrm{RH}, 48 \mathrm{~h}\right)$, with respective controls without aging. Radicle protrusion from 0 to $72 \mathrm{~h}$ of imbibition and 7 after $\mathrm{d}$ at $25^{\circ} \mathrm{C}$, number of normal and abnormal seedlings and dead seeds, and dry matter accumulation (plumule, radicle and total), were measured Molecular characterization of treatments was carried out using RAPD markers, and dendrograms were constructed. Radical protrusion was significantly susceptible to the $\mathrm{HH}$ treatment, while $\mathrm{DH}$ injuries were expressed as reductions in number of normal seedlings and dry matter accumulation, as well as higher proportion of dead seeds. Seeds of var. 'Oaxaca' stood out for their ability for radicle protrusion and generation of normal seedlings with high capacity to accumulate biomass, both in controls and under $\mathrm{HH}$ conditions. The genomic fingerprint was specific for each variety and in dendrograms both control seeds and those subjected to either type of aging, became separated with a specific coefficient of similarity for each variety: 'Oaxaca' (31.6\%), 'Cocotitlán' (25.8\%), 'Puebla' (19.6\%) and 'Cuijingo' (18.6\%). These values might be related to the genetic aptitude to tolerate or restore damages caused on DNA by artificial aging, directly manifested as better physiological performance of 'Oaxaca' seeds.

Index words: Zea mays, germination, genomic fingerprint, seed longevity, RAPDs.

\section{INTRODUCCIÓN}

En México aún se cultivan maíces criollos (Zea mays L.) porque poseen características de adaptación específicas para una región geográfica o de consumo para un sector de la población. Es deseable entonces depurarlos, o utilizar su variación genética mediante fitomejoramiento para incrementar sus rendimientos. Además, estos criollos constituyen la base genética sobre la cual se realiza la actividad agrícola tradicional, de modo que es prioritario su conocimiento básico (Hernández y Esquivel, 2004).

En los Valles Altos Centrales de México (en los Estados de Puebla, Tlaxcala, México e Hidalgo) se cultivan alrededor de 1.5 millones de hectáreas de maíz, de las cuales $85 \%$ 
son de temporal (secano) y de ellas $15 \%$ se siembran con maíz criollo pigmentado, azul principalmente; de estas últimas se estima una cosecha anual de 300 mil toneladas (Antonio et al., 2004).

Los colores del grano de maíz (negro, morado, azul o rojo) se deben a la presencia de pigmentos en la capa de aleurona, en el pericarpio o en ambas estructuras de la semilla (Salinas et al., 1999; Hernández-Uribe et al., 2007); en particular, la antocianina azul se encuentra en la capa de aleurona (Beltrán et al., 2001).

Además de su exótico y atractivo color, el maíz azul posee antioxidantes (flavonoides) y antimutagénicos (Pedreschi y Cisneros-Zeballos, 2006), así como un mejor sabor (Antonio et al., 2004), atributos sensoriales que han elevado su demanda en el mercado (Hernández-Uribe et al., 2007) y su precio ha superado al del maíz amarillo e incluso al del blanco.

A pesar de la existencia de numerosas variedades criollas de maíz azul y de ser muy apreciado por los productores de autoconsumo y más recientemente por consumidores urbanos, estas variedades tienen serias limitantes para su almacenamiento por su alta susceptibilidad al ataque de las plagas y por la rápida pérdida de vigor y viabilidad de sus semillas (Salinas-Moreno et al., 2010), aspectos relacionados con el tipo de endospermo (harinoso o vítreo). Sin embargo, la gran mayoría de ellas carece de una descripción varietal precisa.

Gutiérrez-Hernández et al. (2009) señalaron las limitaciones intrínsecas de las metodologías convencionales de caracterización varietal, y adujeron que las técnicas moleculares de identificación genotípica son más fidedignas porque al no interaccionar con el ambiente, reconocen directamente las diferencias genéticas entre individuos a nivel del ADN y generan una huella genómica específica para cada variedad.

La amplificación aleatoria del ADN polimórfico (RAPD, por sus siglas en inglés), ha sido documentada como un procedimiento confiable para la determinación de la identidad genética de las especies de cultivo y en particular para maíz (Gutiérrez-Hernández, et al. 2009.), aunque también se ha documentado que su precisión no es suficiente para detectar cambios genómicos en soya (Marcos-Filho y McDonald, 1998). Por otra parte, existen protocolos más actuales para la obtención de huellas genómicas como la PCR iniciada con microsatélites solos o anclados, o bien la amplificación aleatoria del polimorfismo de microsatélites (Valadez y Kahl, 2005), que proveen mayor información de los genomas examinados.
La metodología RAPD consiste en utilizar iniciadores de 10 nucleótidos de longitud $(\mathrm{pb})$ con una composición de guanina y citosina mayor a $50 \%$, los cuales se alinean con el ADN genómico, se aparean las bases complementarias $y$, mediante variaciones cíclicas de temperatura, se sintetizan bandas o amplicones de 200 a 2000 pb por la acción de una ADN polimerasa termoestable (Valadez y Kahl, 2005).

Los fragmentos amplificados se despliegan según su peso molecular durante la electroforesis en agarosa o poliacrilamida; algunos de ellos pueden ser genotípico-específicos y por tanto útiles para determinar la identidad varietal, así como para el fitomejoramiento asistido por marcadores moleculares.

Las bandas diferenciales entre genotipos se originan por el cambio de un par de bases, por rupturas y fragmentaciones estructurales, por deleciones que modifican o eliminan el sitio de inserción del iniciador, o por traslocaciones que separan los sitios de acoplamiento del iniciador a una distancia mayor a $2500 \mathrm{pb}$, a la cual ya no hay amplificación (Xena, 2000); se han reportado segmentos del ADN con mayor susceptibilidad a la degradación (Marcos-Filho y McDonald, 1998).

Con el envejecimiento de las semillas se eleva la frecuencia de las disrupciones genómicas que provocan alteraciones moleculares y funcionales del ADN (McDonald, 1999), las cuales pueden ser reparadas durante la imbibición seminal con una eficiencia dependiente del genotipo y de la intensidad de los daños (Gutiérrez-Hernández et al., 2009), o bien manifestarse como anormalidades morfológicas en las plántulas o con la muerte seminal.

El objetivo del presente trabajo fue determinar el efecto del envejecimiento artificial de semillas de cuatro variedades criollas de maíz azul en su aptitud germinativa y huella genómica.

\section{MATERIALES Y MÉTODOS}

Se utilizaron semillas de cuatro variedades criollas de maíz con aleurona azul: 'Cuijingo', 'Cocotitlán', 'Puebla' y 'Oaxaca', provenientes respectivamente de Cuijingo y Cocotitlán, Amecameca, México (2400 msnm), Oriental, Puebla (2600 msnm) y Valles Centrales de Oaxaca (1800 msnm). El endospermo de las tres primeras es harinoso y el de la última vítreo o semicristalino; la semilla usada de todas ellas se produjo en el 2007 por el Programa de Maíz Pigmentado del Campo Experimental Valle de México del Instituto Nacional de Investigaciones Forestales, Agrícolas y Pecuarias, organismo que donó el material genético indicado. La cosecha fue manual y las semillas se almacenaron con un contenido de humedad de entre 8 y $10 \%$, en botes de lámina 
cerrados, y depositados en una bodega con temperatura de 10 a $15{ }^{\circ} \mathrm{C}$, ubicada en Chapingo, Edo. de México. En esta localidad la temperatura y precipitación media anuales son de $15{ }^{\circ} \mathrm{C}$ y $645 \mathrm{~mm}$, respectivamente (García, 1988).

\section{Tratamientos y diseño experimental}

Los experimentos se efectuaron en el año 2009 bajo un arreglo factorial $4 \times 3$, donde el factor 1 fue la variedad de maíz azul ('Cuijingo', 'Cocotitlán', 'Puebla' y 'Oaxaca'), y el factor 2 fue el tipo de envejecimiento: calor húmedo $(\mathrm{CH}$, $41{ }^{\circ} \mathrm{C}$ y $100 \% \mathrm{H} \mathrm{R}$, por $72 \mathrm{~h}$, en una incubadora VWR ${ }^{2}$, USA), y calor seco (CS, $60{ }^{\circ} \mathrm{C}$ y $0 \% \mathrm{H} \mathrm{R}$, por $48 \mathrm{~h}$, en un horno Scorpion Sci. ${ }^{\circledR}$, USA); y como testigos se usaron semillas no sometidas a envejecimiento artificial. Los 12 tratamientos fueron distribuidos en un diseño de bloques al azar con cuatro repeticiones de 25 semillas.

\section{Análisis fisiológico}

Protrusión radicular. Las semillas se colocaron en cajas Petri (una por repetición) con papel filtro y $10 \mathrm{~mL}$ de agua bidestilada, en un cuarto de incubación a $25{ }^{\circ} \mathrm{C}$, con cuatro repeticiones de 25 semillas. En ellas se evaluó el porcentaje de protrusión radicular (PR) desde 0 hasta $72 \mathrm{~h}$ de imbibición (Fragoso-Pérez et al., 2006).

Prueba de germinación normal. Con el mismo tamaño de muestra anterior, las semillas se germinaron envueltas en toallas de papel húmedo que se enrollaron, se colocaron verticalmente dentro de bolsas de plástico y se introdujeron en un cuarto de incubación a $25 \pm 4{ }^{\circ} \mathrm{C}$ (ISTA, 1999). A los $7 \mathrm{~d}$ se contaron los porcentajes de plántulas normales $(\mathrm{PN})$, anormales (PA) y la presencia de semillas duras o muertas sin actividad metabólica aparente (SM).

Materia seca. En el mismo experimento anterior se cuantificó el peso seco (mg/plántula) acumulado en plúmula, radícula y total (PSP, PSR y PST, respectivamente).

\section{Análisis estadístico}

Las variables fisiológicas se analizaron con el paquete estadístico SAS (SAS Institute, 2002), a través de un análisis de varianza correspondiente a un factorial $4 \times 3$. La comparación de medias se hizo con el método de Tukey $(\alpha=0.05)$. Previamente a su análisis, los datos porcentuales se transformaron con la función arco seno $\sqrt{\mathrm{x}}$ con el fin de ajustarlos a una distribución normal (Reyes-Castañeda, 1980).

\section{Análisis molecular}

Se aisló ADN de 100 mg de embriones extraídos manualmente de las semillas de cada tratamiento, los cuales se lavaron dos veces con agua bidestilada y se secaron superficialmente con papel absorbente; después se cuantificó el ADN con el protocolo del CIMMYT (2006). Para la amplificación aleatoria del ADN polimórfico (RAPD) se probaron 10 iniciadores de $10 \mathrm{pb}$ con secuencia aleatoria de la serie E de Qiagen ${ }^{\circledR}$ (Operon, Co.) y tres de la serie $G$ de Roth ${ }^{\circledR}$ (Roth, Co.); la selección se hizo con base en la nitidez y consistencia de los amplicones (Valadez y Kahl, 2005).

La reacción de amplificación se llevó a cabo en un termociclador Mastercycler ${ }^{\circledR}$ (Eppendorf Sci., USA), en un volumen final de $25 \mu \mathrm{L}$. Los productos de amplificación se separaron mediante electroforesis horizontal en gel de agarosa (1.2 \% p/v, Top Vision ${ }^{\circledR}$, Fermentas Co., USA). Los perfiles de bandeo obtenidos se fotografiaron con un transiluminador Gel Logic 440® (Imaging System, Kodak, USA).

Los fragmentos amplificados para cada iniciador se codificaron como 1 para la presencia de la banda y cero para su ausencia, y se construyó así una matriz básica de datos (MBD) que constó de 63 filas y 13 columnas, en correspondencia con las bandas obtenidas y los 12 tratamientos bajo estudio más el ADN de levadura (Saccharomyces cerevisiae) utilizado como control negativo.

Se construyeron dendrogramas con el programa NTSYSpc (numerical taxonomy and multivariate analysis system, ver. 2.1) (Rohlf, 2000), mediante el método de agrupamiento por pares no ponderado con media aritmética (UPGMA) y el coeficiente de similitud de Jaccard (Dubreuil et al., 2003).

\section{RESULTADOS Y DISCUSIÓN}

\section{Análisis fisiológico}

En el análisis de varianza los factores variedad, tipo de envejecimiento y su interacción fueron significativos $(\mathrm{P} \leq$ 0.05) en la mayoría de las variables de germinación (datos no incluidos); sólo carecieron de significancia protrusión radicular y semillas muertas para el factor variedad, y plántulas anormales y semillas muertas para la interacción variedad x tipo de envejecimiento. Es decir, el desempeño germinativo de las semillas dependió de su constitución genotípica, la modalidad de envejecimiento y la acción conjunta de ambos aspectos.

Las variedades (Cuadro 1) mostraron una respuesta similar ante las condiciones de envejecimiento en todas las variables de la germinación, excepto para peso seco total en el cual Oaxaca tuvo el mayor valor $(\mathrm{P} \leq 0.05)$. Como se advierte, la constitución genotípica de las semillas únicamente afectó la acumulación de biomasa, proceso asociado con el vigor de semilla (Fragoso-Pérez et al., 2006). 
Cuadro 1. Efecto de variedad sobre variables germinativas de semillas de cuatro variedades criollas de maíz azul.

\begin{tabular}{cccccc}
\hline Variedad & $\begin{array}{c}\text { Protrusión } \\
\text { radicular } \\
(\%)\end{array}$ & $\begin{array}{c}\text { Plántulas } \\
\text { normales } \\
(\%)\end{array}$ & $\begin{array}{c}\text { Plántulas } \\
\text { anormales } \\
(\%)\end{array}$ & $\begin{array}{c}\text { Semillas } \\
\text { muertas } \\
(\%)\end{array}$ & $\begin{array}{c}\text { Peso seco } \\
\text { total (mg/ } \\
\text { plántula) }\end{array}$ \\
\hline 'Cuijingo' & $86 \mathrm{a}$ & $44 \mathrm{a}$ & $20 \mathrm{a}$ & $36 \mathrm{a}$ & $1.2 \mathrm{~b}$ \\
'Cocotitlán' & $87 \mathrm{a}$ & $41 \mathrm{a}$ & $21 \mathrm{a}$ & $38 \mathrm{a}$ & $1.0 \mathrm{~b}$ \\
'Puebla' & $82 \mathrm{a}$ & $52 \mathrm{a}$ & $9 \mathrm{a}$ & $39 \mathrm{a}$ & $1.0 \mathrm{~b}$ \\
'Oaxaca' & $90 \mathrm{a}$ & $61 \mathrm{a}$ & $7 \mathrm{a}$ & $32 \mathrm{a}$ & $1.8 \mathrm{a}$ \\
\hline
\end{tabular}

Medias con letras distintas en una columna indican diferencias significativas (Tukey, 0.05).

El factor envejecimiento (Cuadro 2) tuvo mayor incidencia sobre el desempeño germinativo, puesto que sus medias evidenciaron los efectos adversos del deterioro de las semillas, excepto en plántulas anormales, ya que los valores de los testigos fueron superiores $(\mathrm{P} \leq 0.05)$ que en calor húmedo $(\mathrm{CH})$ en cuanto a protrusión radicular, y que el calor seco (CS) en cuanto a plántulas normales y semillas muertas. Destaca también que sólo en biomasa total fueron distintas las tres condiciones de las semillas y que el CS causó los efectos más drásticos $(\mathrm{P} \leq 0.05)$.

Cuadro 2. Efecto del tipo de envejecimiento sobre variables germinativas de semillas de cuatro variedades criollas de maíz azul.

\begin{tabular}{cccccc}
\hline Envejecimiento & $\begin{array}{c}\text { Protrusión } \\
\text { radicular } \\
(\%)\end{array}$ & $\begin{array}{c}\text { Plántulas } \\
\text { normales } \\
(\%)\end{array}$ & $\begin{array}{c}\text { Plántulas } \\
\text { anormales } \\
(\%)\end{array}$ & $\begin{array}{c}\text { Semillas } \\
\text { muertas } \\
(\%)\end{array}$ & $\begin{array}{c}\text { Peso seco } \\
\text { total (mg/ } \\
\text { plántula) }\end{array}$ \\
\hline Testigo & $96 \mathrm{a}$ & $84 \mathrm{a}$ & $11 \mathrm{a}$ & $4 \mathrm{~b}$ & $2.3 \mathrm{a}$ \\
Calor húmedo & $75 \mathrm{~b}$ & $61 \mathrm{a}$ & $18 \mathrm{a}$ & $18 \mathrm{~b}$ & $1.4 \mathrm{~b}$ \\
Calor seco & $91 \mathrm{a}$ & $3 \mathrm{~b}$ & $5 \mathrm{a}$ & $90 \mathrm{a}$ & $0.1 \mathrm{c}$ \\
\hline
\end{tabular}

Medias con letras distintas en una columna indican diferencias significativas (Tukey, 0.05).

En la interacción variedad $\mathrm{x}$ tipo de envejecimiento, la protrusión radicular (Figura 1 ) tuvo una reducción ( $\mathrm{P} \leq$ 0.05 ) con $\mathrm{CH}$, de modo que esta fase inicial de la germinación fue más susceptible a esta modalidad de envejecimiento, tal vez porque estas condiciones posibilitaron el inicio de la germinación y porque los eventos metabólicos implicados en ella hayan ocurrido de una manera deficiente en este ambiente desfavorable. Esto indicaría que la brotación radicular es un suceso físico promovido por la rehidratación de los tejidos seminales (Bewley y Black, 1994), pero se deriva de procesos previos como refuncionalización de membranas, síntesis de macromoléculas, división celular, etc. (Sánchez et al., 2005), los cuales resultaron dañados por el CH en etapas tempranas de la germinación ( 0 a 72 h).

Los efectos adversos del CS fueron significativos $(\mathrm{P} \leq$ 0.05) hasta la formación de plántulas (7 d), en términos del incremento en la mortandad de semillas (Figura 4) y de la reducción tanto de las plántulas potencialmente productivas (Figura 2) como de la biomasa (Figura 5). Este menoscabo del desempeño germinativo podría atribuirse a los daños causados al ADN por esta condición de envejecimiento, tales como aberraciones cromosómicas y cambios

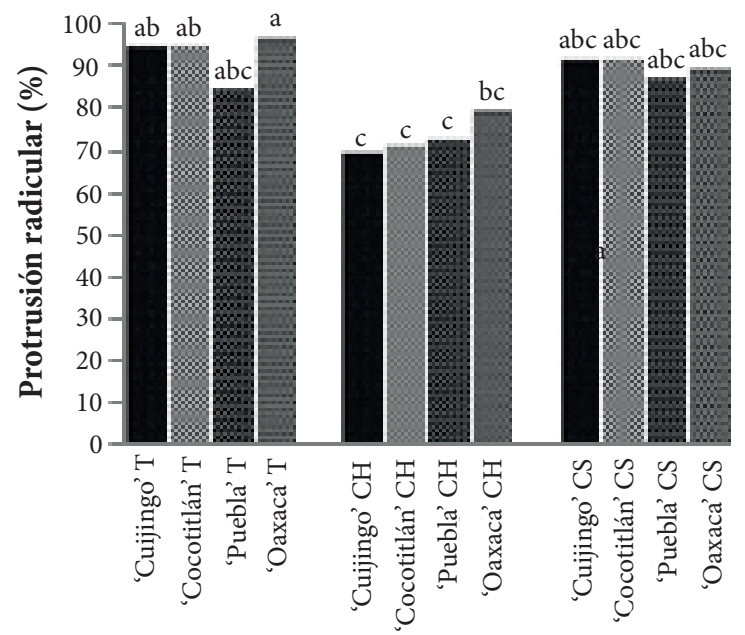

Tratamientos

Figura 1. Protrusión radicular en semillas de cuatro variedades de maíz azul. $\mathrm{T}=$ testigos; $\mathrm{CH}=$ calor húmedo $\left(41{ }^{\circ} \mathrm{C}, 100 \% \mathrm{HR}, 72 \mathrm{~h}\right) ; \mathrm{CS}=$ calor seco $\left(60{ }^{\circ} \mathrm{C}, 0 \% \mathrm{HR}, 48 \mathrm{~h}\right)$. Columnas con la misma letra son significativamente iguales (Tukey, 0.05).

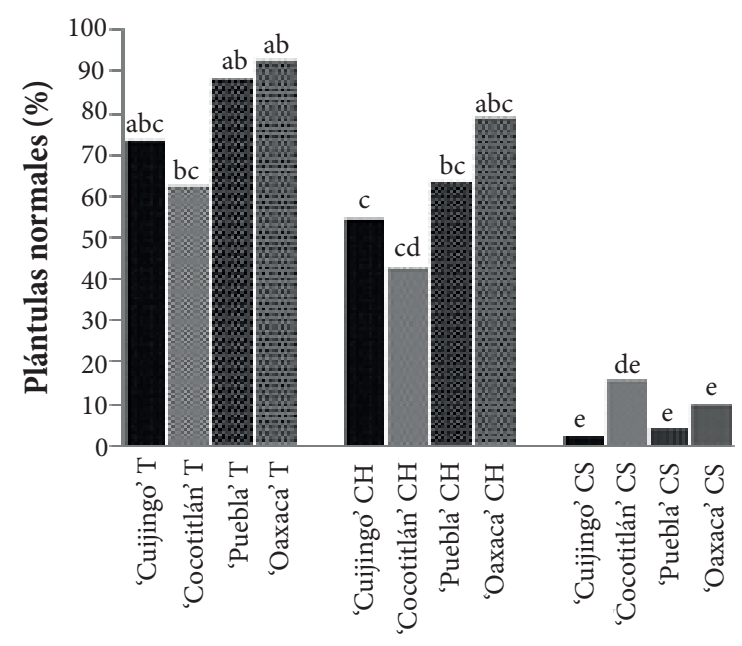

Tratamientos

Figura 2. Plántulas normales obtenidas en la germinación de semillas de cuatro variedades de maíz azul. $\mathrm{T}=$ testigos; $\mathrm{CH}=$ calor húmedo $\left(41{ }^{\circ} \mathrm{C}, 100 \%\right.$ $\mathrm{HR}, 72 \mathrm{~h}) ; \mathrm{CS}=$ calor $\operatorname{seco}\left(60^{\circ} \mathrm{C}, 0 \% \mathrm{HR}, 48 \mathrm{~h}\right)$. Columnas con la misma letra son significativamente iguales (Tukey, 0.05 ).

en su secuencia (McDonald, 1999).

Las referidas alteraciones moleculares del $\mathrm{ADN}$ pueden traducirse en problemas fisiológicos, anormalidades morfológicas o muerte seminal (Fragoso-Pérez et al., 2006), pero en este estudio no se detectaron diferencias en plántulas malformadas para el factor envejecimiento (Cuadro 2) ni entre tratamientos (Figura 3), lo cual sugiere que este aspecto no reflejó la condición metabólica de las semillas, como fue el caso de la biomasa, de las plántulas normales y de las semillas muertas. 


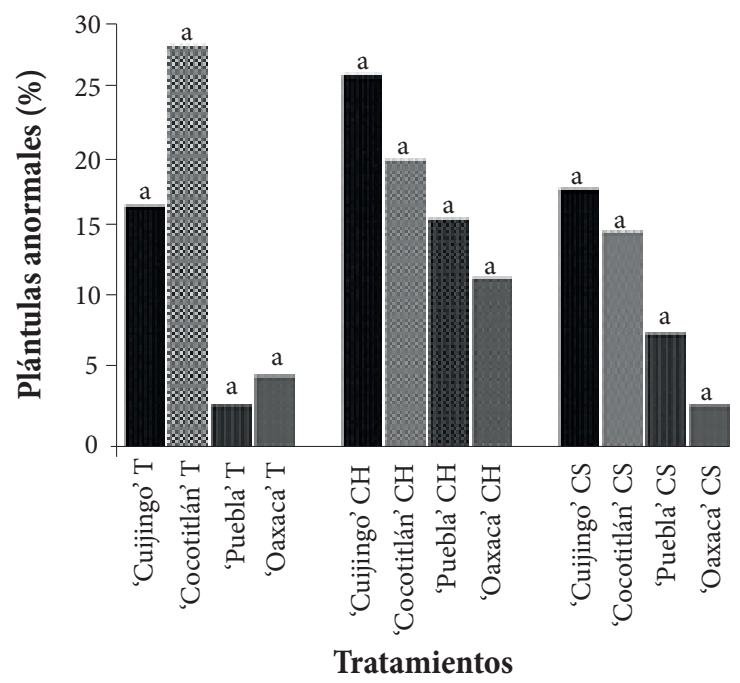

Figura 3. Plántulas anormales obtenidas en germinación en semillas de cuatro variedades de maíz azul. $\mathrm{T}=$ testigos; $\mathrm{CH}=$ calor húmedo $\left(41{ }^{\circ} \mathrm{C}, 100 \%\right.$ $\mathrm{HR}, 72 \mathrm{~h}) ; \mathrm{CS}=$ calor seco $\left(60^{\circ} \mathrm{C}, 0 \% \mathrm{HR}, 48 \mathrm{~h}\right)$. Columnas con la misma letra son significativamente iguales (Tukey, 0.05 ).

En protrusión radicular sobresalieron los criollos 'Oaxaca' y 'Puebla', el primero por mantener valores superiores y el segundo por su modesto pero estable comportamiento en las tres modalidades de envejecimiento (que incluyen al testigo). Estos mismos genotipos tuvieron un desempeño semejante en plántulas normales (Figura 2), en tanto que 'Cocotitlán' mostró mayor $(\mathrm{P} \leq 0.05)$ formación de plántulas normales pese al CS, pero fue susceptible a la condición del $\mathrm{CH}$ en la que tuvo mayor $(\mathrm{P} \leq 0.05)$ muerte de semillas (Figura 4).

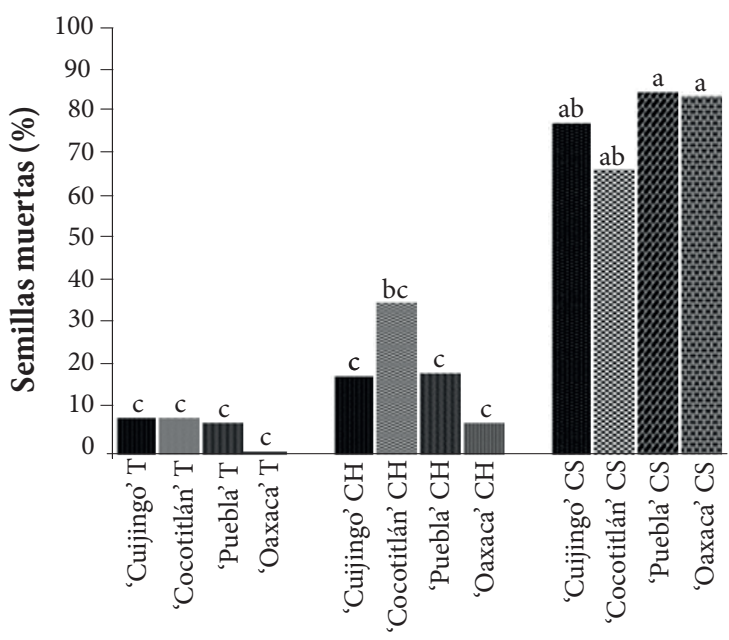

Tratamientos

Figura 4. Semillas muertas detectadas en la germinación de semillas de cuatro variedades de maíz azul. $\mathrm{T}=$ testigos; $\mathrm{CH}=$ calor húmedo $\left(41{ }^{\circ} \mathrm{C}, 100 \%\right.$ $\mathrm{HR}, 72 \mathrm{~h})$; $\mathrm{CS}=$ calor $\operatorname{seco}\left(60^{\circ} \mathrm{C}, 0 \% \mathrm{HR}, 48 \mathrm{~h}\right)$. Columnas con la misma letra son significativamente iguales (Tukey, 0.05).
Entre variedades destacó 'Oaxaca' porque tuvo la mayor $(\mathrm{P} \leq 0.05)$ acumulación de materia seca en las semillas testigo y en las sometidas a $\mathrm{CH}$ (Figura 5); también mostró la mayor $(\mathrm{P} \leq 0.05)$ cantidad de biomasa en vástago y en radícula, atribuible al origen subtropical de su germoplasma y a su textura semicristalina. La variedad 'Cuijingo' se desempeñó de manera semejante a 'Oaxaca' pero con valores algo inferiores, mientras que 'Cocotitlán' y 'Puebla' acumularon las menores cantidades de materia seca.

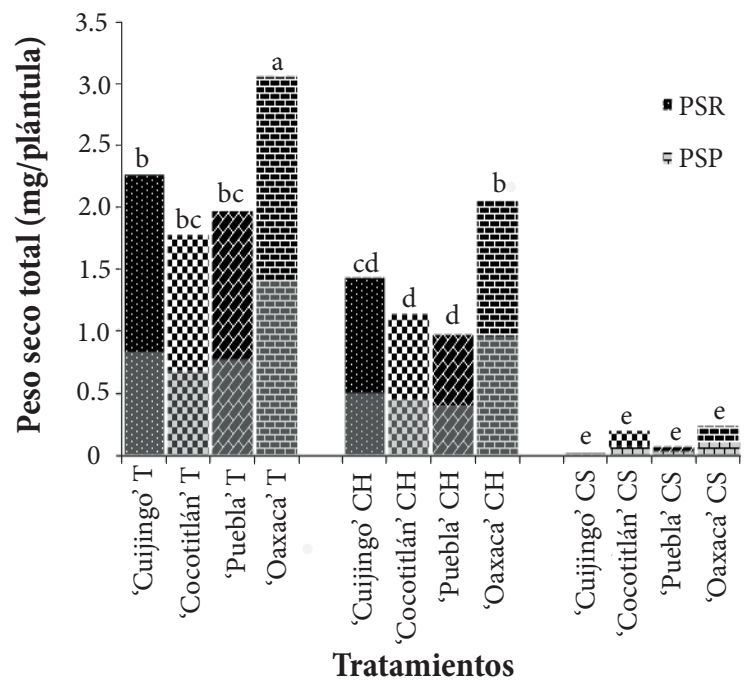

Figura 5. Peso seco de radícula (PSR), de plúmula (PSP) y total (PST) de plántulas formadas por cuatro variedades de maíz azul. $\mathrm{T}=$ testigos; $\mathrm{CH}=$ calor húmedo $\left(41^{\circ} \mathrm{C}, 100 \% \mathrm{HR}, 72 \mathrm{~h}\right)$; $\mathrm{CS}=$ calor seco $\left(60^{\circ} \mathrm{C}, 0 \% \mathrm{HR}, 48 \mathrm{~h}\right)$. Columnas con la misma letra son significativamente iguales (Tukey, 0.05).

Previamente se ha documentado la alteración del proceso de acumulación de biomasa a causa del envejecimiento en las fases iniciales de la germinación (Cruz-Pérez et al., 2003), fenómeno que en este caso ocurrió con intensidades distintas según la modalidad del deterioro y la respuesta genotípica de las variedades.

\section{Análisis molecular}

Los perfiles de bandeo obtenidos (Figura 6) se utilizaron para construir la matriz básica de datos con 63 filas (total de bandas) y 13 columnas (tratamientos y levadura). De ella se derivaron los dendrogramas, cuyos agrupamientos tuvieron coeficientes de correlación cofenética de 0.88 a 0.98 , valores altamente reproducibles (Gutiérrez-Hernández et al., 2009).

La formación de conglomerados o grupos de similitud (Figura 7) asumió dos niveles jerárquicos; el primero de ellos corresponde a la conjunción de los datos genómicos por variedad, y el segundo a la ponderación intravarietal de 

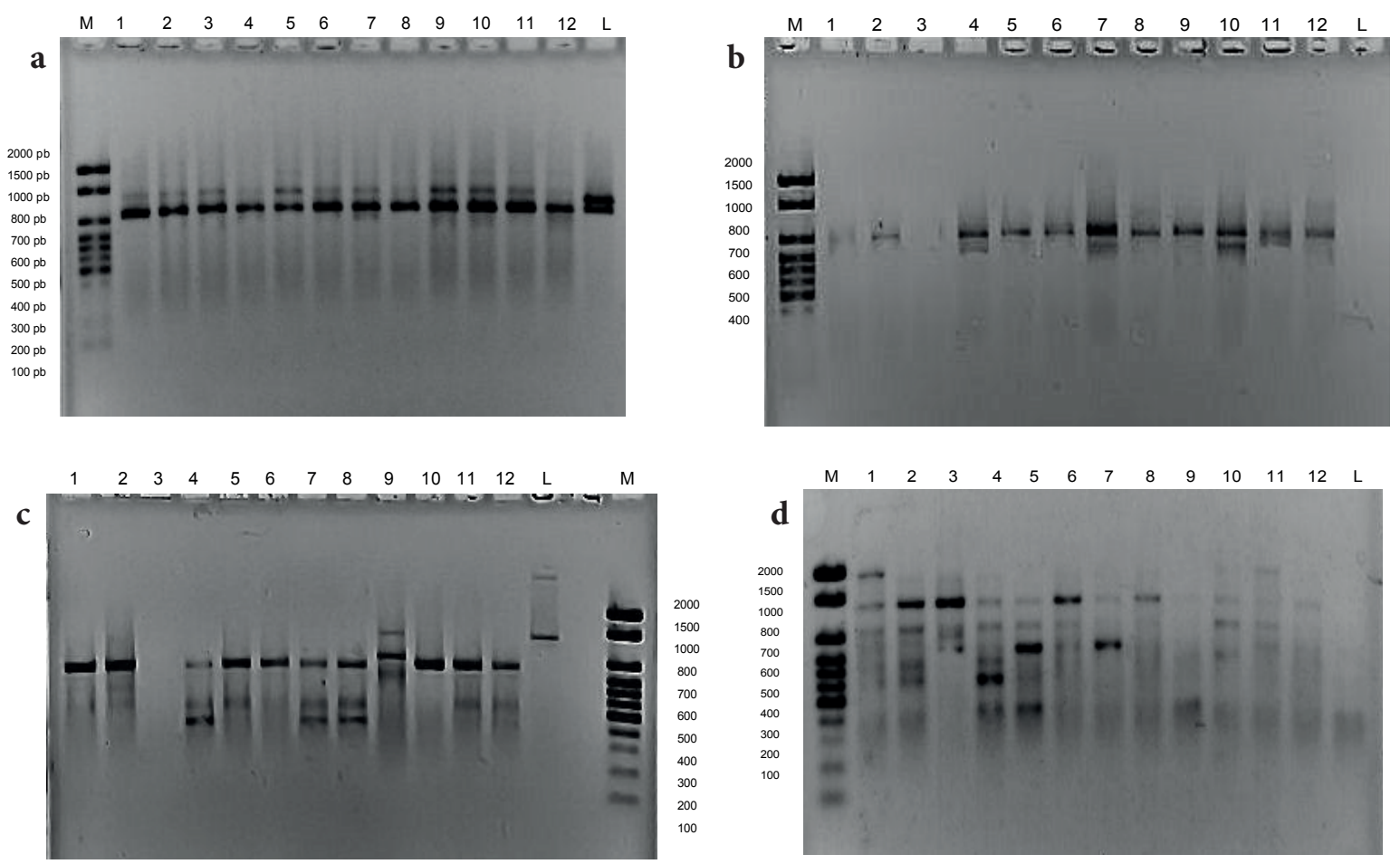

Figura 6. Perfil de bandeo obtenido en 12 tratamientos (carriles 1-12) y la levadura (Saccharomyces cerevisiae) (L, control negativo), para los iniciadores: a) E08; b) E10; c) G13; y d) G15. M = marcador de peso molecular (100 bp DNA ladder, Axygen).

las diferencias genómicas causadas por los tratamientos de envejecimiento aplicados.

Así, la huella genómica resultó específica para cada variedad, independientemente de la condición de germinación de las semillas, y fue dentro de variedades donde los dendrogramas evidenciaron las modificaciones que ocurrieron en los embriones a nivel del ADN durante el envejecimiento artificial. Es decir, los segmentos del ADN testigo, en los que por homología de bases se alinearon los iniciadores y hubo amplificación, deben haberse alterado en su estructura molecular a causa del deterioro impuesto (Xena, 2000), y dado como resultado diferentes perfiles genómicos entre uno y otro tipo de semillas (McDonald, 1999).

Los perfiles de bandeo de semillas testigo y las sometidas a envejecimiento ( $\mathrm{CH}$ y $\mathrm{CS}$ ) fueron semejantes hasta un coeficiente de similitud específico para cada variedad, de 31.6 \% para 'Oaxaca', 25.8 \% para 'Cocotitlán', 19.6 \% para 'Puebla' y 18.6 \% para 'Cuijingo' (Figura 7). A partir de dicho punto se separaron las semillas testigo de las envejecidas, lo que denota un efecto genotípico relacionado con la capacidad para amortiguar, tolerar o restaurar los daños infligidos al ADN por el envejecimiento artificial, cuya mayor expresión se da en 'Oaxaca', seguida de 'Cocotitlán', 'Puebla' y 'Cuijingo', de acuerdo con sus coeficientes de similitud.

Para el primero de los niveles jerárquicos mencionados, es posible suponer que los marcadores RAPDs cumplieron su cometido al separar los perfiles genómicos de cada material genético y que dentro de éstos hubo semillas con distinto grado de envejecimiento artificial (Gutiérrez-Hernández et al., 2009); sin embargo, con el segundo no se logró una discriminación total de los tipos de envejecimiento en cada variedad, puesto que se mantuvieron aglomeradas las semillas testigo con las tratadas con $\mathrm{CH}$ en 'Cuijingo', y las de $\mathrm{CH}$ con las de CS en el resto de las variedades (Figura 7), situación que podría deberse a una insuficiente precisión de los marcadores RAPDs (Marcos-Filho y McDonald, 1998). Habría que recurrir a metodologías moleculares más eficientes para una mejor separación de las condiciones de la semilla.

La notoria capacidad de 'Oaxaca' para preservar su ADN pese al envejecimiento, detectada a nivel molecular, se relacionó con su mejor $(\mathrm{P} \leq \mathrm{0.05})$ desempeño fisiológico, dado que fue la variedad de mayor vigor en semillas testigo y deterioradas con $\mathrm{CH}$, por sus valores superiores en protrusión radicular, plántulas normales, semillas muertas y peso seco total (Figuras 1, 2, 4 y 5). Dicha superioridad podría deberse a su origen semitropical y a su endospermo semicristalino rodeado por una rígida capa de almidón vítreo, elementos que pudieran conferirle mayor resistencia a la acción del calor y de la humedad (Salinas et al., 2010), en tanto que el resto de las variedades tienen endospermo harinoso y germoplasma de zonas templadas. 
'Cuijingo'

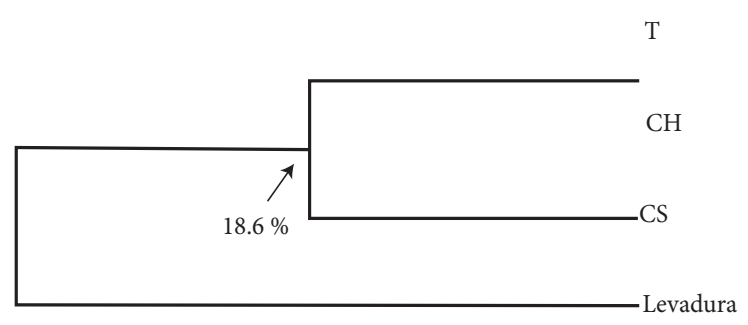

\begin{tabular}{ccccc}
\hline & 0.14 & 0.20 & 0.26 & 0.31 \\
\multicolumn{4}{c}{ Coeficiente de Jaccard }
\end{tabular}

'Puebla'
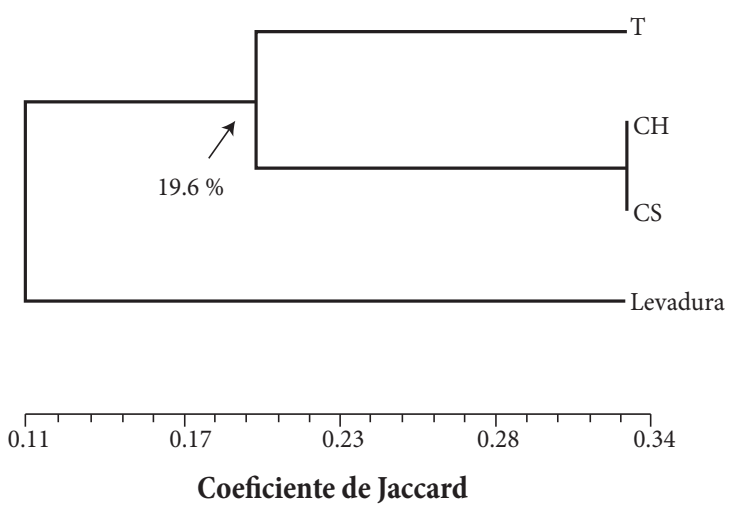

'Cocotitlán'
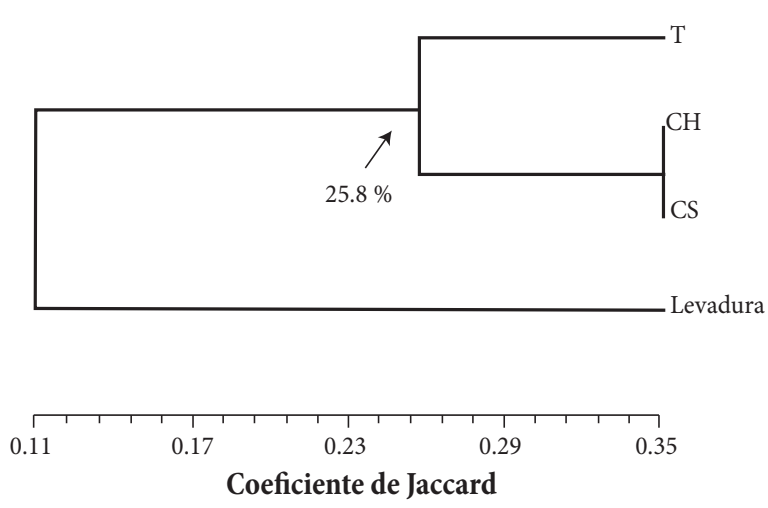

'Oaxaca'

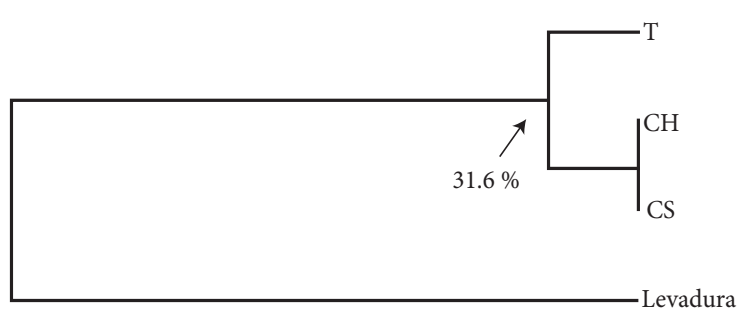

0.11

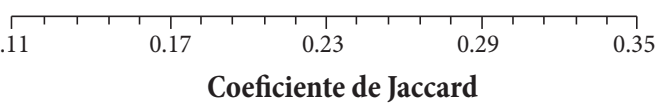

Figura 7. Dendrogramas obtenidos con la matriz básica de datos para cada variedad y sus tipos de deterioro. $\mathrm{T}=$ testigos; $\mathrm{CH}=$ calor húmedo $\left(41{ }^{\circ} \mathrm{C}, 100 \% \mathrm{HR}, 72 \mathrm{~h}\right)$; $\mathrm{CS}=$ calor seco $\left(60^{\circ} \mathrm{C}, 0 \% \mathrm{HR}, 48 \mathrm{~h}\right)$. Método de agrupamiento UPGMA, basado en el coeficiente de similitud de Jaccard. La flecha indica el coeficiente de similitud (\%) en el cual se diversificaron los tratamientos.

\section{CONCLUSIONES}

El envejecimiento de la semilla con calor húmedo disminuyó la protrusión radicular. El calor seco redujo la cantidad de plántulas potencialmente productivas y la acumulación de materia seca, a la vez que incrementó la proporción de semillas muertas. Las semillas de la var. 'Oaxaca' se distinguieron por su aptitud para la brotación radicular y para generar plántulas normales con alta capacidad para acumular biomasa, tanto en condiciones normales de germinación (testigo) como en las de calor húmedo. La huella genómica resultó específica para cada variedad, e intravarietalmente los dendrogramas evidenciaron modificaciones causadas en el ADN por el envejecimiento artificial. Las semillas testigo y las sometidas a las dos modalidades de envejecimiento se ramificaron con un coeficiente de similitud específico para cada variedad: 'Oaxaca' (31.6\%), 'Cocotitlán' (25.8 \%), 'Puebla' (19.6 \%) y ‘Cuijingo' (18.6\%), valores que podrían estar relacionados con la aptitud genotípica para amortiguar, tolerar o restaurar los daños causados por el envejecimiento artificial sobre el ADN, y sería la secuencia molecular de tolerancia al envejecimiento artificial de las semillas ('Oaxaca' > 'Cocotitlán' > 'Puebla' > 'Cuijingo'), orden que solamente se asoció en forma directa con el mejor desempeño fisiológico de las semillas de Oaxaca.

\section{AGRADECIMIENTOS}

A las siguientes instituciones: Secretaría de Investigación y Posgrado del IPN, Programa de Estímulos al Desempeño de los Investigadores del IPN, Comisión de Operación y Fomento de Actividades Académicas del IPN, Facultad de Química de la UNAM y al Instituto Nacional de Investigaciones Forestales, Agrícolas y Pecuarias.

\section{BIBLIOGRAFÍA}

Antonio-M M, J L Arellano-Vázquez, G García-S, S Miranda -Colín, J A Mejía-C, F V González-C (2004) Variedades criollas de maíz azul raza chalqueño. Características agronómicas y calidad de semillas. Rev. Fitotec. Mex. 27:9-15. 
Beltrán-F J, A J Bockholt, L W Rooney (2001) Blue corn. In: Specialty Corns. A R Hallauer (ed). 2nd ed. CRC Press LLC. Boca Raton, FL, USA. pp:293-301.

Bewley J D, A M Black (1994) Seeds: Physiology of Development and Germination. 2nd ed. Plenum Press. N. Y. USA. 445 p.

CIMMYT, Centro Internacional de Mejoramiento de Maíz y Trigo (2006) Protocolos de Laboratorio: Laboratorio de Genética Molecular Aplicada del CIMMYT. 3a. ed. El Batán, Texcoco, Estado de México, México. 62 p.

Cruz-Pérez A B, V A González-Hernández, M C Mendoza-Castillo, M L Ortega-Delgado (2003) Marcadores fisiológicos de la tolerancia al envejecimiento de semilla en maíz. Agrociencia 37:371-381.

Dubreuil P, C Dillmann, M Warburton, J Crossa, J Franco, C Baril (2003) User's Manual for the LCDMV Software (Calculation Software of Molecular Distance Between Varieties) for Fingerprinting and Genetic Diversity Studies. CIMMYT. El Batán, Texcoco, Estado de México, México. 21 p.

Fragoso-Pérez E M, G F Gutiérrez-Hernández, J Virgen-Vargas (2006) Repercusiones físicas y fisiológicas del envejecimiento natural de semillas de cruzas simples de maíz y sus líneas progenitoras. Rev. Fitotec. Mex. 29 (Núm. Esp. 2):75-80.

García E (1988) Modificaciones al Sistema de Clasificación Climática de Köppen. 4a. ed. Universidad Nacional Autónoma de México. México, D. F. 217 p.

Gutiérrez-Hernández G F, E García-Ramírez, J L Arellano-Vázquez, J Virgen-Vargas, G Ramírez-Sotelo (2009) Comparación molecular de la identidad genética de genotipos de maíz de diferente edad. Agron. Mesoam. 20:1-9.

Hernández-C J M, G Esquivel-E (2004) Rendimiento de grano y características agronómicas en germoplasma de maíz de valles altos de México. Rev. Fitotec. Mex. 27 (Núm. Esp. 1):27-31.

Hernández-Uribe J P, E Agama-Acevedo, J J Islas-Hernández, J Tovar, L A Bello-Pérez (2007) Chemical composition and in vitro starch digestibility of pigmented corn tortilla. J. Sci. Food Agric. 87:2482-2487.

ISTA, International Seed Testing Association (1999) International Rules for Seed Testing. International Seed Testing Association. Zurich, Switzerland. $321 \mathrm{p}$.
Marcos-Filho J, M B McDonald (1998) Sensitivity of RAPD analysis, germination and vigour tests to detect the intensity of deterioration of naturally and artificially aged soybean seeds. Seed Sci. Technol. 26:141-157.

McDonald M B (1999) Seed deterioration: physiology, repair and assessment. Seed Sci. Technol. 27:177-237.

Pedreschi R, L Cisneros-Zeballos (2006) Antimutagenic and antioxidant properties of phenolic fractions from Andean purple corn (Zea mays L.). J. Agric. Food Chem. 54:4557-4567.

Reyes-C P (1980) Bioestadística Aplicada: Agronomía, Biología, Química. Ed. Trillas. México, D. F. 213 p.

Rohlf F J (2000) NTSYSpc Numerical Taxonomy and Multivariate Analysis System (version 2.1) User Guide. State University of New York. Exeter Software. USA. $44 \mathrm{p}$.

Salinas-Moreno Y, M Soto-Hernández, F Martínez-Bustos, V A González-Hernández, R Ortega-Paczka (1999) Análisis de antocianinas en maíces de grano azul y rojo provenientes de cuatro razas. Rev. Fitotec. Mex. 22:161-174.

Salinas-Moreno Y, J Soria-Ruiz, E Espinosa-T (2010) Aprovechamiento y distribución del maíz azul en el Estado de México. Folleto Técnico 42. Campo Experimental Valle de México. CIRCE INIFAP. Coatlinchán, México. 56 p.

Sánchez M P, S H Gurusinghe, K J Bradford, J M Vázquez-Ramos (2005) Differential response of PCNA and Cdk-A proteins and associated kinase activities to benzyladenine and abscisic acid during maize seed germination. J. Exp. Bot. 56:515-523.

SAS, Statistic Analysis System (2002) SAS/STAT. Ver. 9. SAS Inst. Inc. Cary NC, USA.

Valadez-Moctezuma E, G Kahl (2005) Huellas de ADN en Genomas de Plantas (Teoría y Protocolos de Laboratorio). Mundi-Prensa. México. $147 \mathrm{p}$.

Xena E N (2000) Una década de aplicaciones del método RAPD: alcances y límites en el estudio de relaciones genéticas en plantas. Acta Cient. Ven. 51:197-206. 